\title{
O Uso do Espaço do Centro de Interpretação do Pampa
}

\author{
The Use of Space Pampa Interpretation Centre \\ Uso del Centro de Interpretación del Espacio Pampa
}

\author{
Clarice de Freitas Pires ${ }^{1}$; Me. Angela Mara Bento Ribeiro ${ }^{2}$; Carlos José de Azevedo \\ Machado ${ }^{3}$. \\ ${ }^{1}$ freitasnice@ bol.com.br, Universidade Federal do Pampa; \\ ${ }^{2}$ angetur.ribeiro8@gmail.com, Universidade Federal do Pampa; \\ ${ }^{3}$ cjmaninho@gmail.com, Universidade Federal de Pelotas.
}

\begin{abstract}
Resumo
Este artigo faz uma análise dos diferentes usos do espaço da chamada Enfermaria Militar, na cidade de Jaguarão, Rio Grande do Sul, Brasil. Este espaço já serviu para variados usos: quando hospital militar, quando escola, quando serviu de prisão política, quando virou ruína, quando virou parque e quando novamente virou apenas ruína, e agora como perspectiva futura enquanto Centro de Interpretação do Pampa. Utilizamos para sua elaboração fontes primárias (documentos existentes, fotos, etc.) e fontes secundárias oriundas de estudos já realizados. A partir dos dados coletados, apresentamos o envolvimento da comunidade demonstrando seu sentimento de pertencimento e identidade com o espaço analisado, ao mesmo tempo, propomos uma discussão para possibilidades futuras de uso pela comunidade após a construção do Centro de Interpretação do Pampa.
\end{abstract}

Palavras-chave: Espaços de memória, usos, pertencimento.

\begin{abstract}
This article analyzes the different uses of space called the Military Infirmary in the city of Jaguarão, Rio Grande do Sul, Brazil. This space has served for various uses: as military hospital, when school when served as a political prison when turned ruin when turned park and when again turned only downfall, and now as a future perspective as Pampa Interpretation Centre. Used for its elaboration primary sources (existing documents, pictures, etc.) and secondary sources derived from previous studies. From the collected data, we present community involvement demonstrating their sense of belonging and identity with the analyzed space at the same time, we propose a discussion to future possibilities for use by the community after construction of the Pampa Interpretation Centre
\end{abstract}

Keywords: memory spaces, uses, belonging.

\section{Introdução}

No alto do Cerro da Pólvora na cidade de Jaguarão, Rio Grande do Sul, se encontrava as ruínas da antiga Enfermaria Militar onde hoje está em construção o Centro de Interpretação do Pampa (CIP). Lá do alto se observa a cidade, a ponte, o rio e o município uruguaio de Rio 
Branco, sugerindo que tudo é uma terra só, como diz o escritor Aldyr Garcia Schelee ${ }^{1}$. Neste lugar está sendo construído, mantendo-se as paredes na sua estrutura original de ruínas, o chamado CIP. Mas antes deste momento, aquele espaço serviu de variados usos pela comunidade: quando hospital militar, quando escola, quando serviu de prisão política durante a ditadura militar, quando virou ruína, quando virou parque e quando novamente virou apenas ruína, e agora como perspectiva futura enquanto Centro de Interpretação do Pampa, uma espécie de museu multidisciplinar sobre o Bioma Pampa rodeado pelo parque que circunda a área construída. Em todos estes momentos citados do passado, a comunidade sempre se utilizou daquele espaço, de formas diversas em função do momento e da situação em que se encontrava.

A partir desta introdução percebemos a necessidade de buscar analisar os diferentes usos deste espaço, a partir dos dados coletados, e abrir uma discussão para possibilidades futuras de uso da comunidade após a construção do Centro de Interpretação do Pampa.

Partimos do estudo da bibliografia existente, além de entrevistas já feitas com moradores durante o processo inicial do Projeto do CIP, e a partir daí organizar os elementos que demonstrem os diferentes usos deste espaço ao longo do tempo. A metodologia utilizada vem no sentido da Ciência Histórica, visando utilizar fontes primárias (documentos existentes, fotos, etc.) e de fontes secundárias. Desenvolveremos a linha histórica de utilização para chegarmos ao momento atual e posteriormente abrirmos para discussões futuras sobre sua utilização.

Da bibliografia geral utilizamos alguns autores como Pierre Norra e Joel Candau, já da bibliografia específica utilizamos artigos de Alexandre Villas Bôas, o Dôssie de tombamento (Iphan), além de documentos diversos, artigos e reportagens em jornais locais e regionais.

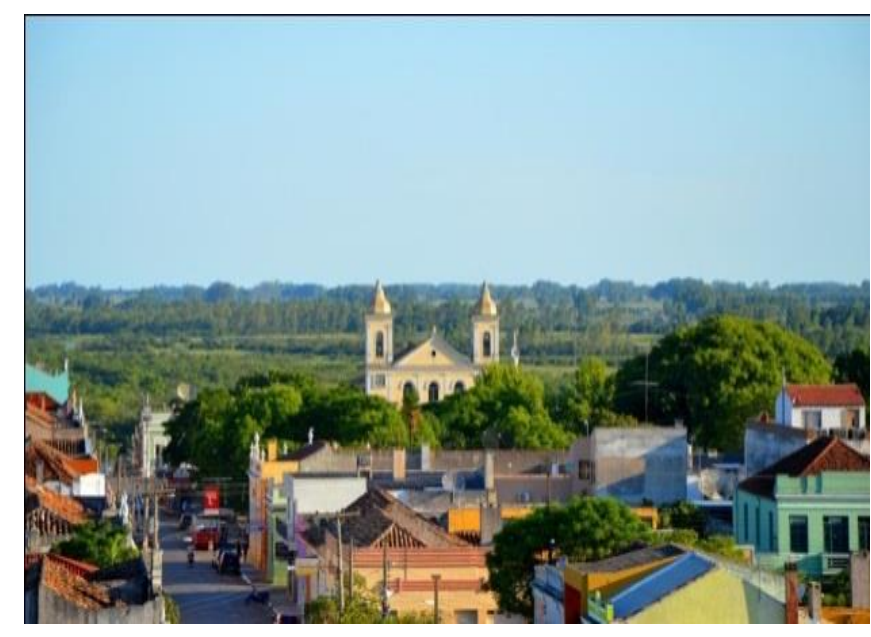

\footnotetext{
1 Aldyr Garcia Schelee é fronteiriço, nascido em Jaguarão (1934), é um autor bilíngue, que escreve e publica sua obra tanto em português como em espanhol. Entre suas obras está "Uma terra só" (2011).
} 
Figura 1 - Imagens do centro histórico de Jaguarão

Fotos: Lino Marques Cardoso

\section{A CIDADE}

A cidade de Jaguarão está localizada no Rio Grande do Sul, Brasil, há $383 \mathrm{~km}$ da capital Porto Alegre e $380 \mathrm{~km}$ de Montevidéu - Uruguai, tendo uma população de 27.931 habitantes (IBGE, 2010), que somado a população de Rio Branco (Uruguai) chega próximo a 45.000 pessoas vivendo no entorno do Rio Jaguarão.

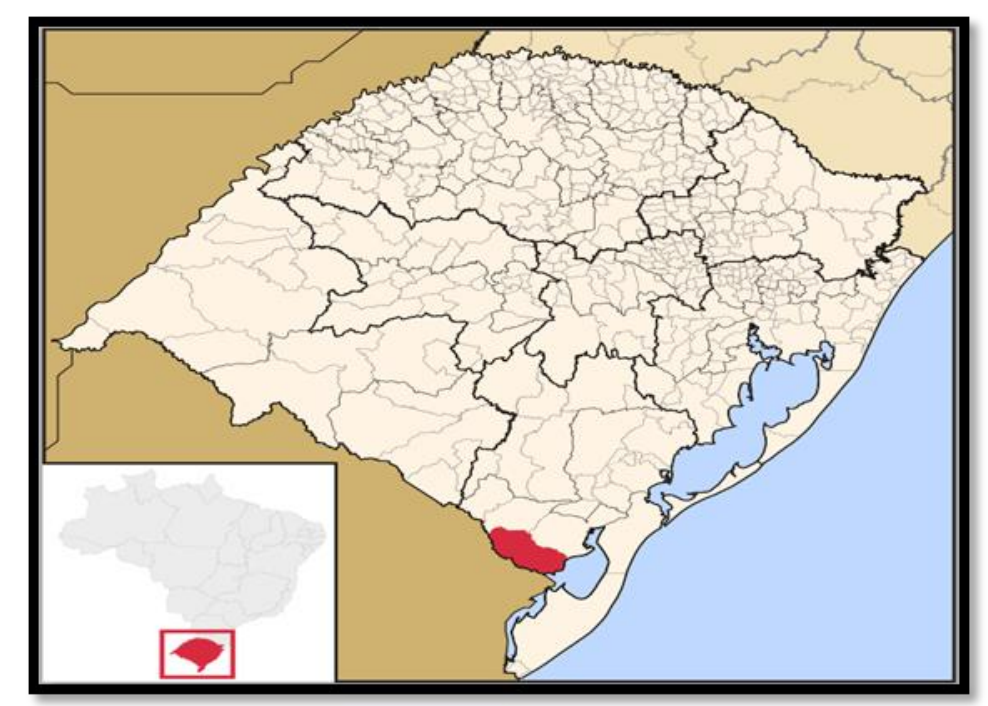

Figura 2 - Localização da cidade de Jaguarão

Fonte: Wikipédia. (https://pt.wikipedia.org/wiki/Jaguarão)

Primeiramente esta região foi um território indígena, com o passar do tempo se tornaram ceramistas nômades da zona pampiana, tendo seus vestígios (potes de barro cozido) classificados pelos arqueólogos como Tradição Vieira. (PEREIRA, 2008). 
Com a vinda dos colonizadores portugueses e espanhóis começaram disputas por estas terras, acarretando assim a assinatura de vários tratados, tendo como o mais importante o Tratado de Madri, assinado em 1750. Com este tratado o estado do Rio Grande do Sul fica com o mapa praticamente igual ao que é hoje, mas na prática somente se concretiza no ano de 1801, com o Tratado de Badajós, que permitiu, através de uma interpretação, aos portugueses se fixarem nestas terras.

Este tratado estabelece a fronteira entre Portugal e Espanha como sendo os seus limites o Rio Jaguarão e o Arroio Chuí, com isso uma Guarda Militar é enviada por Portugal para as margens do Rio Jaguarão, originando assim o povoado que mais tarde se tornaria uma das principais cidades gaúchas do século XIX, e que em pouco tempo passaria de Guarda da Lagoa e do Serrito, em 1802, para se transformar em Freguesia do Divino Espírito Santo de Jaguarão, em 1812.

Na figura a seguir temos uma aquarela de Jean-Baptiste Debret (Villa D'Espiritu Santo Del Serrito). A equipe de Debret foi contratada por D. Pedro II, para retratar lugares do Brasil. Desenho de 1817 (IHGJ).

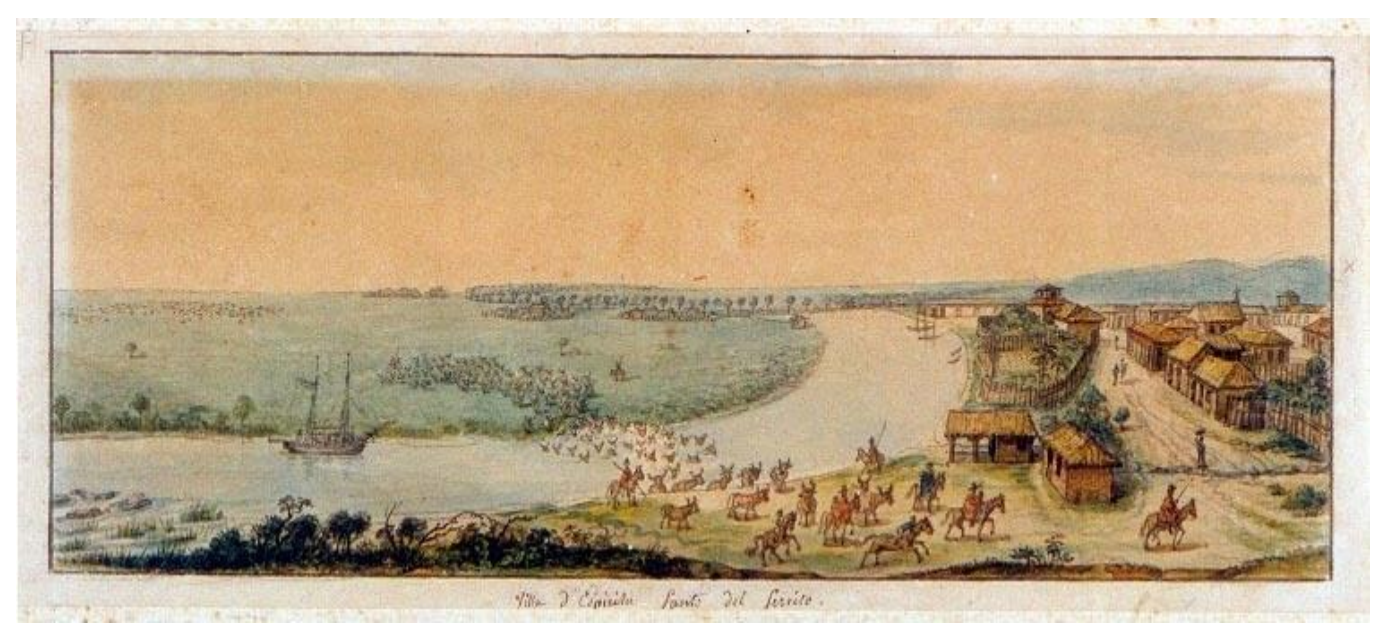

Figura 3 - Desenho da cidade de Jaguarão de 1817 Fonte: Instituto Histórico e Geográfico de Jaguarão

Sua formação se deu através de um acampamento militar às margens do Rio Jaguarão, onde segundo Sergio da Costa Franco, a Guarda do Cerrito foi estabelecida pelo Coronel Manoel Marques de Souza entre os dias 04 e 10 de fevereiro de 1802, com a força aproximada de 260 homens que acabavam de participar da expedição contra Cerro Largo. (FRANCO, 2001, pág.33). 
Com o passar do tempo foi se formando no entorno do quartel um povoado, onde era realizado o abastecimento dos soldados e se desenvolvia também o comércio com os espanhóis do outro lado do rio.

Muitas das aglomerações que se formavam no entorno das instalações militares, criadas após os tratados de 1750 e 1777, foram responsáveis pelo início das povoações urbanas ou por sua elevação à categoria de freguesia. (MARTINS, 2001, p. 28)

Jaguarão foi elevada a vila em 1832, o que na época possuía status de município por sua relativa autonomia. A cidade foi se desenvolvendo com o comércio e através do contrabando com o país vizinho Uruguai. A partir da metade do século XIX começaram as construção dos casarões que hoje ostentam sua imponência aos turistas que visitam Jaguarão, fruto daquele enriquecimento. Em 23 de novembro de 1855 Jaguarão é elevada a Cidade, sendo o décimo segundo município do Estado do Rio Grande do Sul.

\section{O ESPAÇO DO CIP (Antigas ruínas da Enfermaria Militar)}

Em Jaguarão está em construção o Centro de Interpretação do Pampa (CIP), que será uma espécie de museu utilizando-se de muita tecnologia e áudio visual, conforme Projeto da Brasil Arquitetura.

O projeto elegeu o Bioma Pampa como elemento norteador da criação de um Centro de Interpretação do Pampa (CIP), onde as ruínas revitalizadas abrigariam um museu de concepção tecnológica e interativa, assim como equipamentos culturais: auditório conjugado com anfiteatro e prédio de apoio e de exposições temporárias (VILLAS BÔAS; COSTA, in Cadernos Jaguarenses, 2013, pág. 40).

A cidade de Jaguarão por estar em uma região de conflitos e ser uma cidade de fronteira, sempre possuiu um importante efetivo militar, colocando-se assim a necessidade de uma estrutura de apoio o que levou ao estabelecimento de quartéis e a necessidade de um hospital militar. Por este motivo no final do século XIX foi erguido o prédio para abrigar este hospital ficando conhecido como Enfermaria Militar, apesar de todo o pessoal médico envolvido e sua grande estrutura física.

Ponto de passagem de exércitos em trânsito, foco de incipientes charqueadas, entreposto comercial à beira da fronteira móvel de duas nações em gestação, a Guarda do Cerrito não poderia ter sido uma idílica aldeia camponesa, obediente ao sino da igreja e sermões do vigário. Era certamente um lugar de vida aventurosa, sujeita não somente aos respingos das refregas guerreiras, como ao impacto das ambições destacadas entre toda a espécie de pioneiros que se instalavam junto à fronteira (FRANCO, 2001, pág. 39). 
Franco ainda comenta na referida obra que antes de ser construída a então Enfermaria, havia um projeto para um forte naquele local, mas que não chegou a ser construído. No ano de 1880, início da construção, estava na direção o Capitão Carlos Soares, tendo sido finalizada no ano de 1883. O prédio foi construído em estilo neoclássico com aproximadamente sete mil metros quadrados, tendo como dependências quartos para os enfermos, divididos para soldados e oficiais, gabinete para atendimento médico, cozinha, farmácia, dormitório para médicos e enfermeiros e alojamento para os presos enfermos. Com seu formato em "U”, possuía um pátio interno, suas portas eram em arco voltadas para o pátio, com um grande corredor que dava acesso às dependências. Sua fachada era com grandes janelas, a porta de entrada era grande com um frontão em cima e duas colunas e um porão devido à elevação do terreno. (VILLAS BÔAS; COSTA, in Cadernos Jaguarenses, 2013, pág.33).

O prédio encontra-se em uma das partes mais altas da cidade chamada de Cerro da Pólvora, tendo uma vista privilegiada da cidade e da fronteira com o país vizinho Uruguai, com a divisa feita pelo rio Jaguarão. Como nos dizem Villas Bôas e Costa (2013, p. 34) "a denominação de Cerro da Pólvora derivaria desta fortificação ou dos explosivos utilizados durante a construção da Enfermaria Militar”.

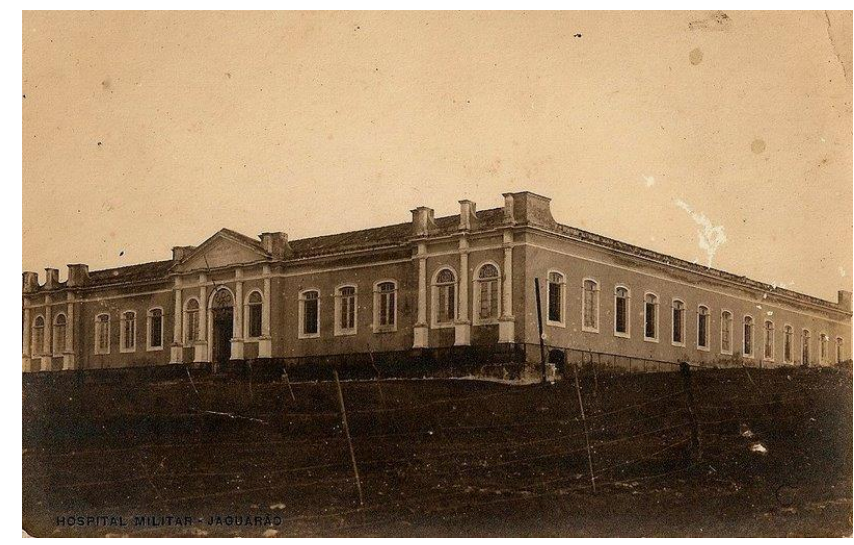

Figura 4 - Enfermaria Militar

Fonte: Arquivo do Instituto Histórico e Geográfico de Jaguarão

Os enfermeiros militares realizavam esporadicamente o atendimento à população, como a aplicação de injeções. Porém a importância desse local como instalação de saúde, foi decaindo durante a década de sessenta, tendo suas funções originais gradativamente esvaziadas. O prédio passou então a ser usado como escola de aplicação e utilizado como 
prisão, durante o golpe civil-militar de 1964, para os presos políticos. Teve suas funções totalmente encerradas quando a $13^{\circ}$ Regimento de Cavalaria foi transferido para a capital, Porto Alegre, como podemos notar no depoimento da senhora Eci Duarte.

Eu dei aula lá na enfermaria. Sim... era um pré-estágio que a gente fazia. Nós éramos alunas do pré-estágio normal na época. E antes de começar... fazia... e como ficou, antes era uma enfermaria... até sessenta, sessenta e poucos, sessenta foi o ano que a gente veio pra Jaguarão... a minha irmã disse que em 62 ela foi visitar alguém lá que era nosso amigo. Ele tava no quartel e que tava doente, então ainda era enfermaria. Ai depois terminou... não sei se foi o quartel que se mudou, não sei o que aconteceu, que acabou... que não tinha mais enfermaria lá... como ficou assim sem uso. Aí as irmãs resolveram fazer uma escola, um anexo da escola normal... tinham uma diretora, uma equipe. (INSTITUTO DE MEMÓRIA E PATRIMÔNIO, 2011).

\subsection{O Abandono Institucional}

As instalações foram abandonadas e, em um determinado período, entre o final da década de sessenta e o início da década de setenta, a própria comunidade depredou o prédio. Foi uma depredação abrupta. Contada por depoimentos orais, uma pessoa teria pedido autorização ao Comandante da Guarda remanescente para retirar algum material, assim o restante da população do entorno começou a depredação do prédio. (VILLAS BÔAS; COSTA, in Cadernos Jaguarenses, 2013, pág.36).

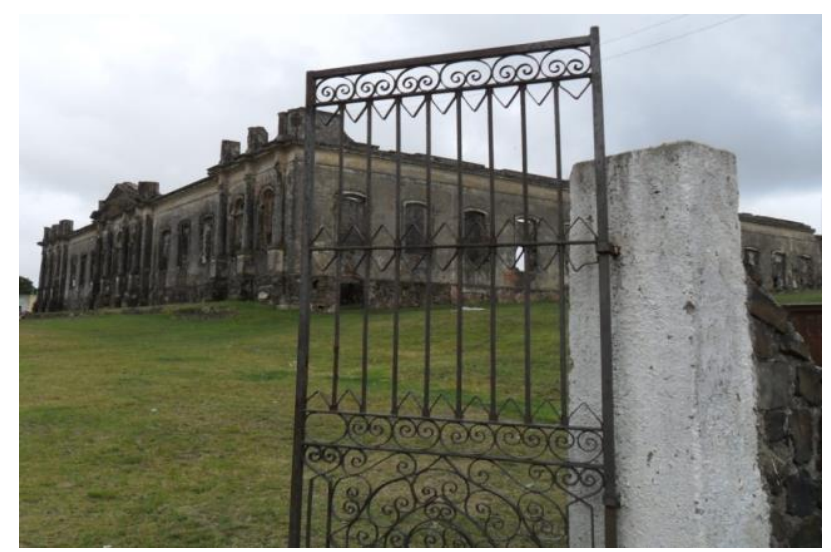

Figura 5 - As ruínas, vista do portão de entrada, 2011.

Fonte: Arquivo pessoal de Clarice de Freitas Pires 
Há uma controvérsia no tempo de duração da depredação, uns dizem que foi em um dia, outros em uma semana, mas os indícios são de que foi em um curto espaço de tempo que a Enfermaria Militar se transformou em ruínas. Da parte institucional, não houve um empenho para conter ou recuperar aquele imóvel, que permaneceu como ruína até os dias atuais, onde, enfim está em processo de revitalização.

Neste período de ruínas, o prédio foi usado como ponto de visitas ocasionais pelos turistas, em virtude da sua localização e das histórias que envolvem o local. A comunidade do entorno usava o espaço como lazer, para tomarem o seu chimarrão, as crianças brincavam e servia também como ponto de encontro dos jovens, que não raramente deixavam inscrições nas paredes do prédio. O local também servia como ponto de uso de drogas, onde os dependentes faziam uso de todo tipo de drogas, principalmente no período noturno, justamente por não haver iluminação.

O projeto elegeu o Bioma Pampa como elemento norteador da criação de um Centro de Interpretação do Pampa (CIP), onde as ruínas revitalizadas abrigariam um museu de concepção tecnológica e interativa, assim como equipamentos culturais: auditório conjugado com anfiteatro e prédio de apoio e de exposições temporárias. (VILLAS BÔAS E COSTA, in Cadernos Jaguarenses, 2013, p..40).

O prédio está localizado no ponto mais alto da cidade de Jaguarão, em um terreno rochoso denominado de Cerro da Pólvora, na Rua da Paz esquina com a Rua João Azevedo, local que foi escolhido por ser estratégico na visualização de toda a cidade e do país vizinho Uruguai, período em que estava bem forte o sentimento de preocupação com a fronteira, em função do ataque sofrido em janeiro de 1865 pelos blancos, grupo político e militar uruguaio que disputava o poder com outro grupo no país vizinho, os colorados.

Um aumento do prédio se deu no ano de 1915 com a construção de um necrotério e uma capela. Com o abandono pelo exército, no ano de 1940, o prédio passou a funcionar como escola e alojamento e serviu também como prisão política e militar.

\title{
3.2 As Ruínas e Seu Uso
}

\author{
CERRO DA PÓLVORA (Tadeu Gomes) \\ Virgem Maria \\ Que céu bonito \\ Que claridade no Cerro da Pólvora \\ Pedreiras pedras de fogo \\ Luzindo no meu coração
}


Enfermaria abandonada

Mal assombrada sem serventia

Aqui do alto eu vejo a fronteira

A Ponte as águas do Rio Jaguarão

Em roda do Cerro da Pólvora

Porteira da Ponte Mauá

Que "adentra" pelo Uruguai

Nesta fronteira eu já fui moleque

Cresci no vento feito andorinha

Em sonhos e fantasias

andanças e temporais

Quando a saudade me atormenta

E a tormenta traz a escuridão

Ventos do sul açoitam minh'alma

Ponteios de solidão

Esta letra feita por Tadeu Gomes no começo dos anos de 1980, gravada em disco por Hélio Ramirez, músico e biólogo jaguarense, retrata bem a visão de muitas gerações que por ali passaram, sobretudo a partir da década de 1970. Como diz a letra da música, a visão lá do alto é bonita, clara, reluzente, pode até assustar, mas a beleza da vista da cidade é o que mais agrada. A dimensão da beleza da fronteira com o país vizinho é vista através da Ponte e do Rio Jaguarão, divisa natural entre os dois países. Muitas pessoas a utilizavam para ver a cidade, namorar, tomar mate. Os moradores do entorno as utilizavam como extensão de suas casas, onde colocavam varais para roupas no seu redor, as crianças usavam o espaço como recreação.

No ano de 1982 dois jovens jaguarenses que estudavam arquitetura na Faculdade Ritter do Reis, na cidade de Porto Alegre e após na Universidade Federal de Pelotas, protagonizaram um movimento denominado Jaguar, que possibilitou um levantamento arquitetônico em Jaguarão na forma de inventário ao qual denominaram de Projeto Jaguar.

\footnotetext{
O grupo Jaguar, integrado por estudantes, está tentando preservar o prédio, e a sua reivindicação principal é o seu tombamento, com a construção de um parque, no terreno em frente às Ruínas, pois julgam que a área cedida ainda é muito pequena. $\mathrm{O}$ prédio já foi cedido pelo III Exército à Prefeitura Municipal. (FOLHA DA TARDE, 1984, pág.31).
}

Na noite de 24 de fevereiro de 1984, se realizou a II Vigília Musical pela Enfermaria Militar de Jaguarão, onde mais de mil pessoas se fizeram presentes no Cerro da Pólvora, o que superou as expectativas dos organizadores. Durante a Vigília os estudantes falavam às pessoas que se faziam presente, sobre o Projeto e sobre as próprias ruínas. 
Durante toda a noite, os estudantes mantiveram um bar no local. Ali mesmo podiam ser encontradas camisetas no valor de Cr\$ 4 mil, com o desenho do prédio impresso e escrito II Vigília pela Enfermaria, sendo que até o final da noite haviam sido todas vendidas. Outro ponto forte desta II Vigília Musical foi o bom clima em eu tudo transcorreu, não havendo nem a necessidade de interferência da Brigada Militar, que se manteve a noite toda no local. (ibid., 1984).

Assim, este movimento protagonizado num primeiro momento por estudantes jaguarenses, alguns cursando Arquitetura em Porto Alegre e Pelotas, e por professores destas faculdades, recebe apoio na comunidade, em especial professores, estudantes e dirigentes municipais. Isto provocou um novo ciclo que vai influenciar as estruturas políticas locais, a partir do início dos anos 80 , porém o processo de recuperação vai ser acelerado somente a partir de 2009 com uma ação municipal de aproximação mais direta com o Instituto do Patrimônio Histórico e Artístico Nacional (IPHAN), ocasionando o tombamento nacional do centro histórico e da Enfermaria Militar. Até então suas ruínas eram tombadas apenas pelo Instituto do Patrimônio Histórico e Artístico do Estado do Rio Grande do Sul (IPHAE). A partir daí houve uma parceria entre município e Universidade Federal do Pampa para que esta última assumisse a gestão do CIP.

O projeto considerado "pioneiro", desenvolvido no começo dos anos 80, denominado "Jaguar", englobou diversas ações além do inventário, entre elas a utilização de espaços culturais como o Teatro Esperança e a valorização das ruínas da Enfermaria Militar. [...]. Após a primeira eleição depois da Ditadura (1985), o prefeito eleito, Fernando Correa Ribas, entusiasmado com a movimentação deste projeto, institucionaliza algumas atividades e começa a organizar a revitalização das Ruínas da Enfermaria, acarretando a criação de um parque no local. Com a morte deste prefeito em um acidente automobilístico o parque acabou levando seu nome. Porém na década de 90 as novas gestões acabam gerando um novo e forte abandono deste local. (MACHADO, in Jornal Fronteira Meridional, $15 / 05 / 2015)$.

Segundo Vergara, Zorzi \& Peixoto, (2012, pág. 256-257), ao investigar as ruínas da antiga Enfermaria em seu trabalho intitulado: Arqueologia em campo: Usos e significados atribuídos à antiga Enfermaria Militar de Jaguarão - RS, eles fizeram uma entrevista com um artista que fez um desenho nas paredes da ruína:

Durante a pesquisa arqueológica, conhecemos Bob Alex Araujo, 33 anos, neto de Lenita e sobrinho de Gregório, pessoas que também se inseriram na pesquisa, através de depoimentos relacionados à fase em que a EMJ foi escola. Bob é jaguarense e pinta desde os 11 anos 
de idade. A maioria dos desenhos nas paredes da Enfermaria é de autoria dele. Logo que iniciamos a conversa, caminhando no interior do prédio, Bob parou de frente ao pátio interno, apontou para a antiga capela e disse: "naquela parede caída havia um desenho meu”. Ele se lembrou de várias paredes que foram derrubadas onde havia inscrições de sua autoria. (VERGARA; ZORZI \& PEIXOTO, 2012, pg. 256)

Segundo os autores, Bob contou que fez o desenho no ano de 1996. "No final dos anos 1990, a prefeitura mandou apagar o desenho, pois era apelativo e remetia ao vandalismo.” (Ibid.).

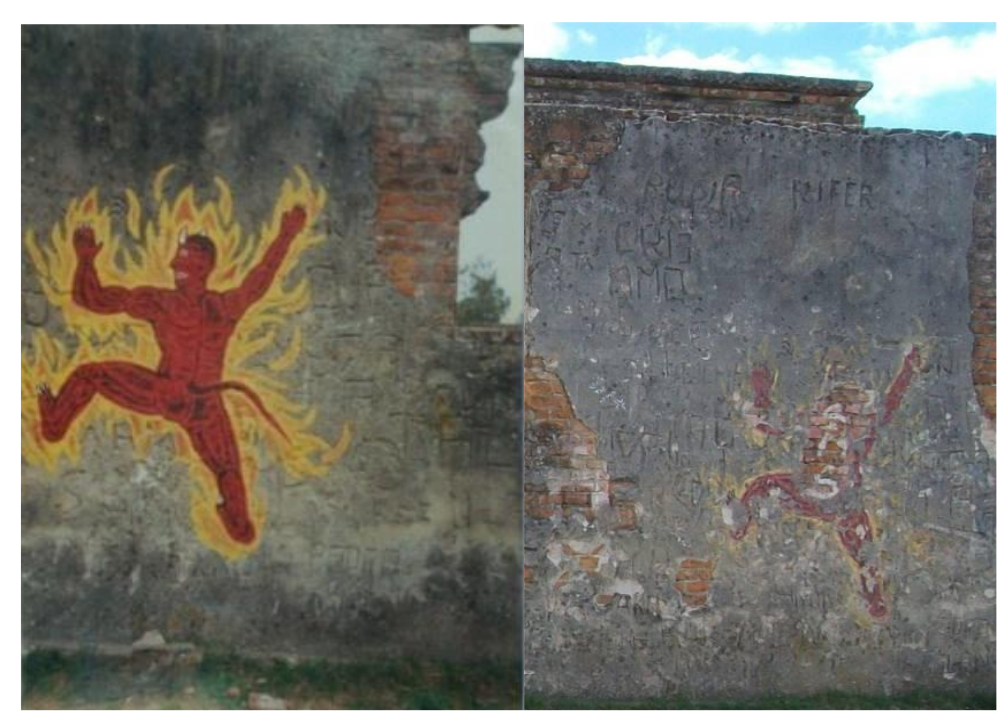

Figura 6 - Desenho de Bob

Fonte: Vergara; Zorzi \& Peixoto, 2012.

No ano de 2009, quando se realizou um movimento em favor da preservação do prédio da antiga Enfermaria Militar, podemos observar o sentimento de identidade e pertencimento dos moradores para com a cidade de Jaguarão. Percebemos isto nas conversas e depoimentos da comunidade, como também é percebido no momento do ato de abraço realizado no entorno das ruínas, que veremos na foto a seguir: 


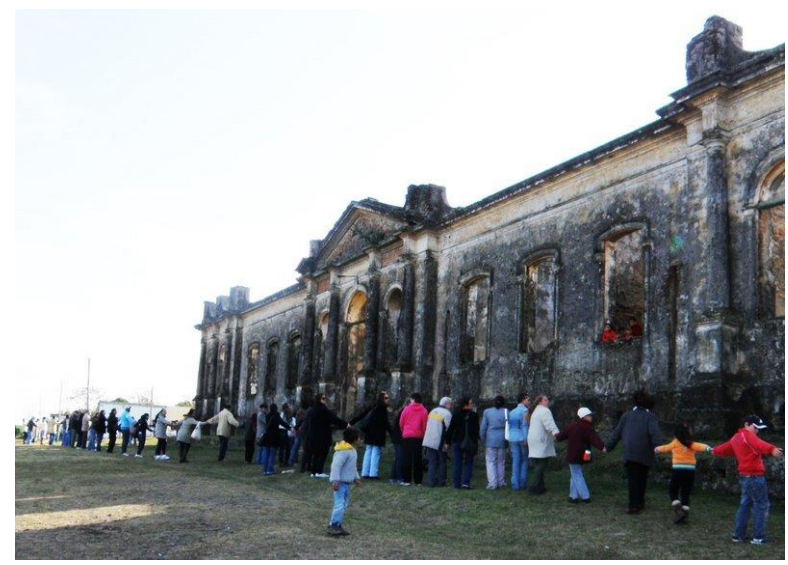

Figura 7 - Ruínas da Enfermaria, momento do "Abraço em defesa do Centro de Interpretação do Pampa".

Fonte: http://www.secultjaguarao.blogspot.com.br/2009_08_10_archive.html, acessado em 28/10/2015.

Com o projeto do arquiteto Marcelo Ferraz da Brasil Arquitetura, este local será transformado em um complexo cultural, que contará com a revitalização do prédio e terá a construção de novas instalações adjacentes. Estas novas instalações contarão com auditório, anfiteatro, salas de ensino e pesquisa e prédios de apoio técnico. O ponto central integrador é o Bioma Pampa, que abrange além do Brasil, a Argentina e o Uruguai.

Analisando o projeto podemos notar que o referencial do prédio como enfermaria fica somente em parte da fachada, pois como podemos ver na foto abaixo seu espaço interno será alterado consideravelmente.

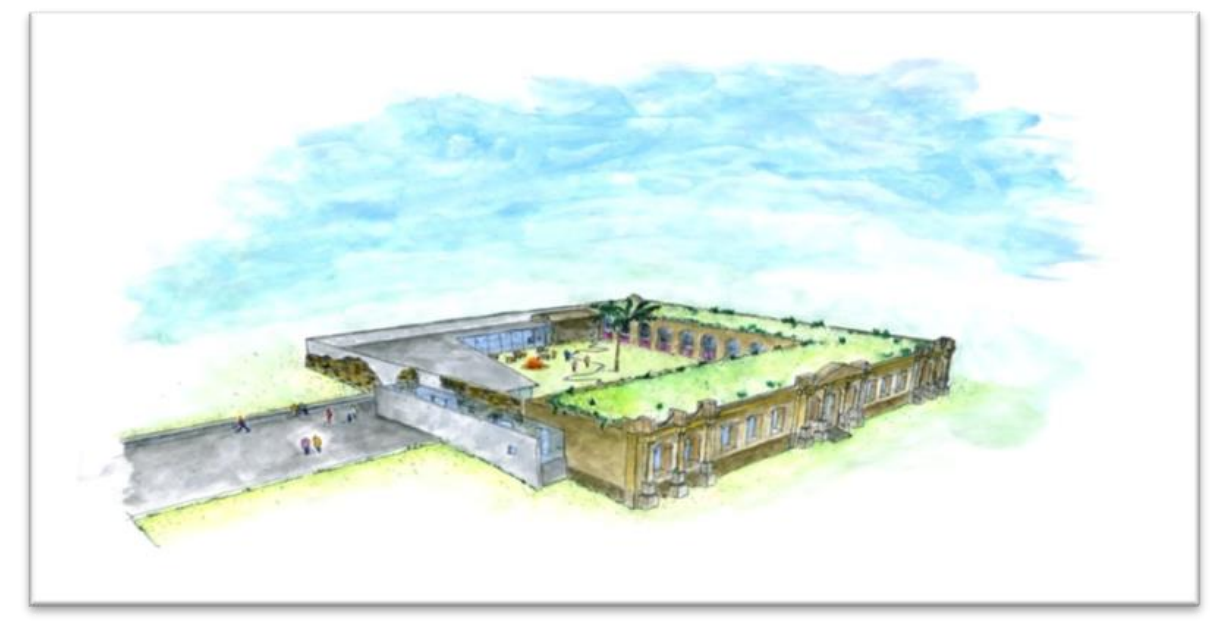

Figura 8 - Revitalização da antiga Enfermaria Militar Fonte: Brasil Arquitetura 


\section{Considerações finais}

Conforme pudemos observar com o exposto, aquele espaço mesmo em momentos diferentes, sempre foi usado pela população. Nos últimos 40 anos, enquanto ruína, e no curto espaço onde funcionou um parque no seu entorno, foi utilizada fundamentalmente como lugar de lazer.

Analisando o projeto da Brasil Arquitetura, percebemos uma ideia de abertura para a comunidade, no que tange a sua área física no entorno. Mas há entendimentos por parte da Universidade Federal do Pampa, por conta da segurança e manutenção daquele espaço, da necessidade de uma cerca no entorno. A preocupação é plausível no nosso entendimento, uma vez que o espaço do parque é extenso, mas a questão levanta uma preocupação que precisa ser analisada: o quanto esta "cerca" afetará a estética da obra, e como será a forma de entrada e passeio pelo "parque da enfermaria", bem como a do prédio do CIP. O que podemos perceber até o momento é que há a preocupação por parte da reitoria em juntar a questão da segurança com o acesso da comunidade, porém o projeto ainda está em execução e ainda não definido efetivamente esta questão.

A importância de a comunidade sentir-se pertencente daquele espaço é que garantirá a continuidade deste como um símbolo importante para a memória da cidade, até porque, este espaço só foi tombando como patrimônio, por conta de sua memória, uma vez que o patrimônio nada mais é do que uma dimensão desta. (Candau, 2011). Se considerarmos ainda, conforme Pierre Norra (1993), que é um lugar funcional, pois foi adquirindo a função de alicerçar memórias coletivas, está num lugar específico, com toda a sua materialidade e simbólico uma vez que representa sentidos que a comunidade dá a cidade, o espaço onde hoje está se constituindo o Centro de Interpretação do Pampa é um genuíno Lugar de Memória, portanto, a comunidade deve estar atenta ao seu futuro, para que o mesmo se torne não apenas um referencial para a América Latina, mas continue como um referencial para a memória da cidade.

\section{Referências}

BÔAS, Alexandre dos Santos Villas. Cadernos Jaguarenses. Vol. 6. Jaguarão: IHGJ, 2014.

BÔAS, Alexandre dos Santos Villas; COSTA, Heloísa Helena Fernandes Gonçalves da. Cadernos Jaguarenses. Vol. 5. Jaguarão: IHGJ, 2013. 
BRASIL ARQUITETURA. Projeto Centro de Interpretação do Pampa. Disponível em: http://brasilarquitetura.com/projetos/. Acessado em 23/06/2015.

CANDAU, Joel. Memória e Identidade. São Paulo, Contexto, 2011.

CUNHA, Magda Rodrigues. Enfermaria tem mais de cem anos. Jornal Folha da Tarde, edição de 28/02/1984, pág. 31 .

DUARTE, Eci. Salvamento Arqueológico da Enfermaria Militar: Depoimento [ago. 2010]. Entrevistadores: Luciana Peixoto e Mariciana Zorzi. Pelotas: INSTITUTO DE MEMÓRIA E PATRIMÔNIO, 2011. Depoimento concedido ao projeto de salvamento arqueológico da Enfermaria Militar de Jaguarão-RS

FRANCO, Sérgio da Costa. Gente e coisas da Fronteira Sul: ensaios históricos. Porto Alegre: Sulina, 2001.

IBGE. Jaguarão. Disponível em:

http://www.cidades.ibge.gov.br/painel/populacao.php?lang=\&codmun=431100\&search=\%7C jaguarao. Acessado em: 25/06/2015.

INSTITUTO DO PATRIMÔNIO HISTÓRICO E NACIONAL (IPHAN). Dossiê de Tombamento do Conjunto Arquitetônico e Paisagístico de Jaguarão. Porto Alegre: Ministério da Cultura; IPHAN, 2010.

MACHADO, C.J.A., Jornal Fronteira Meridional. Edição de 06 de maio de 2015.

MARTINS, Roberto Duarte. A ocupação do espaço na fronteira Brasil-Uruguay: a construção da cidade de Jaguarão. Barcelona: 2001.

NORA, Pierre. "Entre Memória e História: A problemática dos lugares". Tradução: Yara Aun Khoury. In, Projeto História , Revista do Programa de Estudos Pós-Graduados em História e do Departamento de História. São Paulo, PUC SP, dez. 1993, nº 10, pp. 07-28.

PEREIRA, Claudio Corrêa. Minuanos/Guenoas: os cerritos da bacia da Lagoa Mirim e as origens de uma nação pampiana. Porto Alegre: Fundação Cultural Gaúcha - MTG, 2008.

WIKIPEDIA. Jaguarão. Disponível em: https://pt.wikipedia.org/wiki/Jaguarão. Acessado em: 25/06/2015.

RIBEIRO, Ângela Mara Bento; MACHADO, Carlos José de Azevedo; ÁVILA, Cristiane Bartz de; RIBEIRO, Maria de Fátima Bento. Apostila de apoio Pronatec/IFSUL, cursos de Condutor Cultural Local e Agente de Informações Turísticas, 2014.

RIBEIRO, Maria de Fátima Bento \& MELO, Alan Dutra. Centro de interpretação do pampa em Jaguarão: Rio Grande do Sul - Brasil.

SCHLEE, Aldyr Garcia. Uma terra só. Porto Alegre: ardotempo, 2011

VERGARA, ZORZI \& PEIXOTO. Arqueologia em campo: usos e significados atribuidos à antiga enfermaria militar de jaguarão-rs IN: MICHELON, Francisca Ferreira; MACHADO 
JÚNIOR , Cláudio de Sá; GONZÁLEZ, Ana María Sosa(Orgs). Políticas públicas e patrimônio cultural: ensaios, trajetórias e contextos. Pelotas: Ed. da Universidade Federal de Pelotas, 2012. 